\title{
Dental practice in the UK in 2015/2016. Part 3: aspects of indirect restorations and fixed prosthodontics.
}

\author{
Jum'ah, AA
}

http://hdl.handle.net/10026.1/13304

\subsection{8/sj.bdj.2019.95}

British Dental Journal

Springer Nature [academic journals on nature.com]

All content in PEARL is protected by copyright law. Author manuscripts are made available in accordance with publisher policies. Please cite only the published version using the details provided on the item record or document. In the absence of an open licence (e.g. Creative Commons), permissions for further reuse of content should be sought from the publisher or author. 
Dental practice in the UK in 2015/2016 - Part 3:

\section{Aspects of indirect restorations and fixed prosthodontics}

Jum'ah $\mathrm{AA}^{1}$, Creanor $\mathrm{S}^{2}$, Wilson $\mathrm{NHF}^{3}$, Burke $\mathrm{FJT}^{4}$ and Brunton $\mathrm{PA}^{5}$.

1 Jordan University of Science \& Technology

Faculty of Dentistry, Department of Conservative Dentistry

Irbid 22110, P.O.Box 3030

Jordan

aajuma@just.edu.jo

2 Medical Statistics, Plymouth University Peninsula Schools of Medicine \& Dentistry, Plymouth, UK

3 King's College London Dental Institute, London, UK

4 University of Birmingham, Birmingham, UK

5 University of Otago

Sir John Walsh Research Institute

Faculty of Dentistry

310 Great King Street

Dunedin 9054

New Zealand

paul.brunton@otago.ac.nz 


\section{Abstract}

This paper reports data which helps identify changes and trends in the provision of indirect fixed prostheses in general dental practice in the UK. Objectives: To determine by means of an anonymous, self-report questionnaire, the current trend in the provision of fixed prosthodontics treatments, with a special emphasis on the choice of treatment modalities, techniques and materials. Methods: The data presented were extracted from the data obtained from a validated, 121-question questionnaire distributed at random to general dental practitioners in the UK attending postgraduate meetings in $2015 / 2016$, with a wide distribution of locations. Results: A response rate exceeding $66 \%$ was achieved. Amalgam and light cured composite were the preferred material for core build-up of vital teeth for around $62 \%$ of the respondents. Dentine pins were still being used by $66 \%$ of the respondents. The vast majority of respondents (92\%) used a post and core to restore root treated teeth. Fibre posts were the most commonly used (63\%) type of preformed post among the respondents. Using the opposing and adjacent teeth as a reference to control tooth structure reduction during vital tooth preparation was the most common method, used by $42 \%$ of the respondents. Addition cured silicone impression materials were the most frequently used impression material $(78 \%)$. The surveyed practitioners were equally split between precious and non-precious metals as substructure for indirect restorations. Glassionomer luting cements $(47 \%)$ and resin-based cements $(52 \%)$ were the most commonly used to cement porcelain fused to metal and zirconia indirect restorations, respectively. Laboratory-made aesthetic veneers were prescribed by half of the respondents, while a third of them preferred direct resin composite as a veneer material. Conclusions Within the limitations of the study, it was concluded that there has been an increase in the use of adhesive bonding and metal-free restorations. Amalgam and dentine pins continued to be used, contrary to international trends. Studies of the type reported are considered important in investigating trends and developments in dentistry.

\section{Keywords}

General dental practice, Indirect restorations, Fixed prosthodontics, Post, Core build-up, Impression, Veneers. 


\section{Introduction}

The continuous evolution of dental practice has in part been driven by new developments in materials and technology. The introduction of tooth-coloured, high-strength ceramic materials in tandem with advancements in digital and adhesive dentistry have played a significant role in changing prosthodontics and restorative dentistry practice. In parallel, patients increasingly demand speedy and aesthetic treatments and this has led to significant changes to the treatments offered by dental professionals.

In the UK, over $90 \%$ of dentistry is provided in primary dental care by general dental practitioners (GDPs). ${ }^{(1,2)}$ How GDPs practice, the materials and techniques they use is therefore of considerable interest. Previously, questionnaire studies have investigated primary dental care in the UK. ${ }^{(1,3-5)}$ Questionnaires of this type provide valuable information about the current practising habits of general dental practitioners and allow for a comparison of practice with the available evidence for best practice, where it exists. In addition, trends and gaps in practice can be identified, which might be a focus for postgraduate education initiatives in the future.

The aim of this third series of a three-part questionnaire-based study, which commenced in 2004, to investigate the selection and use of materials and associated techniques by UK dental practitioners with respect to indirect restorations and fixed prosthodontics.

\section{Materials and Methods}

As described in the first and second papers in the present series, ${ }^{(5,6)} 500$ hard copies of a piloted questionnaire, comprising 121 questions, were distributed in a random manner to dentists in general dental practice (GDPs) in the UK attending a wide variety of postgraduate courses across the UK, at which at least one of two of the authors (NHFW and FJTB) were presenting or otherwise contributing to in some way. This aimed to recruit study participants with a wide geographic distribution from across the UK, who expressed a willingness to complete and return the questionnaire, using the stamped addressed envelopes provided. 
There were no inclusion or exclusion criteria for the study, other than the participating dentists confirming that they were in general dental practice in the UK. Many elements of the questionnaire were taken from the questionnaires used in the 2003 and 2008 surveys, $(3,4)$ but with additions to investigate aspects of the clinical practice of dentistry in the UK considered to have changed in the intervening years.

The final questionnaire comprised 121 questions, many of which contained supplementary sections. The questions asked sought information on a wide range of matters, including aspects of the provision of indirect restorations and fixed prosthodontics, specifically:

- How materials were selected for cores and how cores were retained in vital teeth

- How non-vital teeth were restored and the techniques used

- The impression materials or systems used

- Whether full or partial coverage and or metal-free restorations were routinely prescribed

The data obtained from completed questionnaires were collated and analysed using Stata SE software (StataCorp LLC, version 14). Percentages reported are based upon the number of respondents who answered each question, given that not all respondents answered all 121 questions included in the questionnaire.

\section{Results}

\section{Core build-up for extra coronal restorations}

Vital posterior teeth:

The majority of the respondents $(62 \%, n=241)$ indicated that amalgam is one of the two most commonly used materials for this purpose. A similar percentage $(61 \%, n=236)$ of the respondents used light-cured resin composites. Fewer dentists used other types of resinbased materials, including chemically-cured $(8 \%, n=30)$ and dual-cured $(22 \%, n=84)$ resin composites. Conventional, resin modified and reinforced glass-ionomer cements were also used by $12 \%(n=48), 19 \%(n=72)$ and $25 \%(n=97)$ of the respondents, respectively. Interestingly, one participant reported the use of Biodentine ${ }^{\circledR}$ as a core build-up material. 
Ten participants $(3 \%, n=10)$ stated that they do not build teeth up prior to preparation for extra coronal restorations. A large proportion $(34 \%, n=126)$ of the respondents reported the use of dentine pins to retain cores. Table 1.

\section{Post and core systems}

Posts were used to restore root-treated teeth by the majority of respondents $(96 \%, n=370)$. Preformed post systems were very popular among the respondents; fibre posts being most popular $(63 \%, n=243)$. Stainless steel, titanium alloy and pure titanium-based post systems were used by a small percentage of the respondents $(13 \%(n=51) ; 11 \%(n=44) ;$ and $4 \%$ $(n=14)$, respectively). Cast metal post and cores were used by a smaller proportion of respondents (precious metals: 39\% ( $n=149)$ vs. non-precious metals $46 \%(n=175))$. Table 2 .

\section{Preparation of vital teeth for full coverage restorations}

When asked about the control of tooth tissue removal during vital tooth preparation for full coverage restorations, $96 \%(n=208)$ of the respondents reported the use of one or more method. The majority of the respondents $(42 \%, n=90)$ used the opposing and adjacent teeth as a reference to control tooth structure reduction. Estimating the amount of tooth structure reduction in reference to the dimensions of the preparation burs was a technique used by $31 \%(n=67)$ of respondents. The use of depth cutting burs and/or a pre-preparation matrix was favoured by $12 \%(n=26)$ and $12 \%(n=25)$, respectively. Table 3 .

\section{Impressions for crown and bridge work}

Of 386 practitioners, $78 \% \quad(n=299)$ reported the use of addition-cured silicone (polyvinylsiloxane) for taking impressions of prepared teeth. Polyether was the second most used material, at $22 \%(n=35)$. Condensation silicone and alginate were significantly less commonly used $(10 \%(n=37)$ and $9 \%(n=33)$, respectively). Two respondents reported the use of digital impression systems. Automated impression material mixing machines were widely used among the respondents ( $n=379,45 \%)$. Table 4. 


\section{Materials for fixed prostheses}

\section{Metal alloys}

Only $4 \%(n=15)$ reported that they exclusively prescribe metal-free restorations. For those who reported the use of metal-based restorations, just over half $(52 \%, n=189)$ used nonprecious alloys and $43 \%$ of respondents $(n=157)$ reported the use of precious metal alloys. Table 5.

\section{Zirconia}

Of the 376 respondents, $57 \%(n=213)$ reported the use of zirconia-based ceramics as a high strength core for layered restorations. Around one third of those who used zirconia $(34 \%$, $\mathrm{n}=74$ ) reported having significant complications with this type of restorations. Excessive opacity of zirconia-based restorations was reported by $45 \%$ of the respondents $(n=34)$. Two thirds of the respondents $(66 \%, n=48)$ reported chipping of the ceramic veneer layer. Delamination of the ceramic veneer layer was also a common problem reported by $14 \%$ of the respondents $(n=14)$. Unexpectedly, fracture of the zirconia substructure was reported by $26 \%$ of the respondents $(n=19)$. Other problems, such as loss of retention, bulky crowns, and difficulty in cutting and poor contact points were also reported. Table 5.

\section{Materials for aesthetic veneer, inlay and onlay restorations}

Only $10 \%(n=32)$ of the respondent did not prescribe veneers at all. Laboratory made porcelain veneers were prescribed by $51 \%(n=167)$. Of all respondents $36 \%(n=118)$ prescribed direct resin composite veneers. Laboratory made resin composite veneers, CAD CAM milled veneers and preformed resin composite veneers were used by small numbers of respondents $(2 \%(n=5), 1 \%(n=4)$ and $0.3 \%(n=1)$, respectively).

With regard to the production of life-like aesthetic results in inlay and onlay restorations, $43 \%$ $(n=158)$ preferred the use of ceramics. In contrast, resin composite was the first choice for 
such restorations by $29 \%(n=108)$ of the respondents. Out of the 372 respondents, $29 \%$ $(n=106)$ reported that either material will produce good aesthetic results.

\section{Tooth-coloured, metal-free crowns}

The majority of the respondents $(n=327)$ who answered the questions on tooth-coloured, metal-free crowns reported occasional prescription of such restorations $(56 \%, n=213)$. Metal-free crowns were routinely prescribed by $32 \%$ of the respondents $(n=123)$. Only $12 \%$ $(n=46)$ reported that they have never prescribed such restorations. The majority of the respondents prescribed IPS e.max and zirconia based materials for both, anterior and posterior metal-free crowns.

\section{Materials for cementation/bonding \\ Porcelain fused to metal (PFM) restorations}

Glass-ionomer cement was the most popular among the respondents $(47 \%, n=180)$. Resin modified glass-ionomer cement came second $(28 \%, n=108)$ followed by zinc phosphate $(15 \%, n=56)$ and resin composite based luting $(14 \%, n=55)$ cements. Self-adhesive resin cement and resin-based cement, which adheres specifically to metals were used by $13 \%$ $(n=50)$ and $10 \% \quad(n=39)$ of the respondents, respectively. Compomer and zinc polycarboxylate cements were used by very few respondents $(<2 \%)$. Table 6 .

\section{Zirconia crown and bridge restorations}

Resin composite based luting and self-adhesive resin cements were the most popular among the respondents $28 \%(n=88)$ and $23 \%(n=72)$, respectively. Glass-ionomer and resin modified glass-ionomer cements were still used by $18 \% \quad(n=56)$ and $17 \% \quad(n=51)$ of respondents respectively. Zinc phosphate and compomer based cements were used by very by a small number of respondents $(<3 \%)$. Table 6 .

\section{Discussion}

This survey targeted a group of practitioners who attended postgraduate courses. The response rate was good, with the results of this survey being considered to provide a 'snapshot' of arrangements in general dental practice in the UK in 2015/2016. ${ }^{(5)}$ 


\section{Core build-up and preparation of vital teeth}

In comparison to data reported in the 2008 survey, there has been a notable increase in the proportion of practitioners who used light-cured resin composite for the core build-up of vital teeth. ${ }^{(4)}$ Despite intentions to phase-down the use of amalgam in accordance with the Minamata convention, ${ }^{(7,8)}$ amalgam remained a preferred material for the core build-up of vital teeth in the UK. It seems that the majority of the respondents believed that the benefits of amalgam outweigh those offered by alternative core build-up materials and perceived health risks as reported in the second part of this series of papers. ${ }^{(6)}$ As indicated by the 2008 survey, the use of traditional glass-ionomer as a core material for vital teeth continued to decrease. It would appear that increasing numbers of practitioners recognised the superior physical properties of light- and dual-cured resin composites, resin-modified and reinforced glass ionomer cements. Chemically-cured resin composites remained unpopular among practitioners who may prefer to use materials with controlled setting and reduced shrinkage. The incompatibility of the latter with modern, acidic adhesive systems may further discourage their use. ${ }^{(9)}$ Surprisingly, one-third of the respondents reported the continuing use of dentine pins, despite their well-documented drawbacks. ${ }^{(10)}$ Adherence to old school methods, lack of confidence/knowledge in adhesive dentistry or cost pressures are all possible causes for such prescription habits. Research is required to determine the drivers for practitioners persisting with outdated practices. In this context, it may be in the best interests of patients to formulate national guidance on the use of adhesive restorative systems, such as bulk-fill composites for core build-ups, specifically.

Excessive removal of tooth structure during preparation of vital teeth for full coverage restorations jeopardises pulpal health and longevity of the restoration. ${ }^{(11)}$ Thus, limiting tooth structure removal to the extent that it fulfils optimum mechanical and aesthetic requirements is paramount. Using pre-preparation matrices constructed on a waxed-up model is one of the most efficient means to control tooth structure removal. It also enables clinicians to perform 'smart' preparations, especially in the cases of malaligned and or worn teeth. In this 
survey, $12 \%$ of the respondents used this method and a similar percentage used depth cutting burs. The majority of the surveyed clinicians relied solely on clearance in relation to opposing and adjacent teeth, together with the dimensions of preparation burs.

\section{Post and core systems}

The use of posts to restore root treated teeth was very common among the respondents. Preformed posts were preferred by the majority of practitioners. This is understandable, as such posts provide immediate coronal seal, do not require extensive coronal tooth structure preparation, require no technically demanding temporisation and thus, are associated with less inter-appointment microleakage, and are more cost-effective ${ }^{(12)}$. Good retention and retrievability of fibre posts are probably the reasons behind the surge in their popularity. ${ }^{(13)}$ The percentage of clinicians using fibre posts almost doubled since the time of the 2008 survey. The use of cast metal posts remained essentially constant since the 2008 survey. ${ }^{(4)}$ Almost half of the respondents reported a preference for precious or non-precious metals posts. Cast metal has a very high modulus of elasticity in comparison to radicular dentin and increases the risk of root fracture. ${ }^{(14)}$ Cast metal posts are, however, indispensable in certain clinical situations, for example, where a metal diaphragm is required to seal a resorptive defect or fracture line. Additionally, cast posts are invaluable where canal morphology is not compatible with the cross section of preformed posts, however, there are many techniques to customise fibre posts using composite resin materials. Currently, there are claims that the use of posts is incompatible with minimally invasive dentistry. Bonding of resin composite to tooth structure in the pulp chamber and coronal part of the root canal system, as in Nayyar's technique, is considered to be a conservative modality. ${ }^{(15,16)}$ Time will tell if such thinking will be adopted routinely in UK general dental practice.

\section{Choice of impression material}

Since the time of the 2008 survey, little had changed regarding the clinician's choice of impression materials. The majority of clinicians, in this survey, used addition-cured silicone materials, given their accuracy and good handling characteristics. Polyether impression 
material is very rigid and now requires automated mixing, which may explain it not gaining popularity during the period between 2008 and the current survey. Currently, its use being increasingly limited to implant supported prostheses procedures. It remains a cause for concern that $19 \%$ of respondents continued to use suboptimal materials, including condensation silicone and alginate, to record master impressions for indirect restorations. This could be linked to a misguided desire to reduce cost or a failure to recognise the shortcomings of such materials. The use of such materials is contrary to the best interests of patients, and it is suggested that such findings highlight areas for continuing professional development.

The use of digital impressions was limited according to this survey. A previous survey also reported that the majority of UK dentists did not use any part of the digital workflow for provision of indirect restorations. ${ }^{(17)}$ This may be attributed to several factors, including: high cost of the technology, lack of knowledge and training and the limited number of dental laboratories that can process digital scans.

\section{Fixed prostheses}

The findings indicated a notable decrease in the percentage of clinicians who prescribed precious metal alloys (69\% vs. $43 \%)$ in favour of an increased prescription of non-precious counterparts $(27 \%$ vs. $52 \%)$ since the time of the previous survey. ${ }^{(4)}$ Unfortunately, nonprecious alloys have inferior casting properties and marginal fit. Additionally, health-related issues with the 'troublesome' grinding/adjustment of non-precious alloy castings is a critical issue. $^{(18,19)}$

The majority of respondents reported the use of glass-ionomer GIC $(47 \%, n=180)$ or resin modified glass-ionomer $(28 \%, n=108)$ to cement PFM restorations. There was a substantial drop since the time of the 2008 survey, in the percentage of dentists using zinc phosphate cement $(27 \%$ vs. $15 \%){ }^{(4)}$ This might be due to increased awareness of its potential damaging effects of highly acidic and exothermic environment produced during material setting. Additionally, the respondents may have recognised the superior handling properties 
of alternative cements. Resin-based cements are also better alternatives wherever preparations exhibit compromised retentive features. In addition, a reduction in the number of dental schools teaching the use of zinc phosphate cement may have contributed to above finding.

The data obtained in the present study indicated an increased use of zirconia-based ceramics. The dense crystalline structure and the unique transformation toughening mechanism have qualified zirconia to be called 'ceramic steel'. ${ }^{(20)}$ Zirconia possesses high biocompatibility, an optimum soft tissue response and antibacterial properties which collectively enable this material to outperform alternative materials. ${ }^{(21)}$ Recent research indicates that zirconia-based restorations may be found to have a cumulative five-year survival rates of $93.5 \%$ for tooth-supported and $100 \%$ for implant-supported fixed

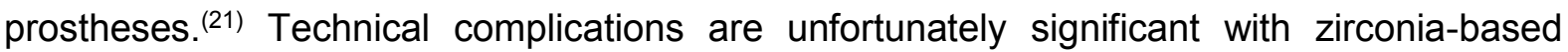
restorations. Porcelain veneer layer chipping or complete delamination is a major concern in such bilayered configurations. ${ }^{(22)}$ Several techniques have been described to overcome this problem, but a consensus is yet to be reached. The use of monolithic or 'full contour' zirconia may be a predictable solution, but with some concerns regarding antagonistic tooth wear. The struggle to mask the grey colour of metal cores has been superseded by the challenge to disguise the 'too white' substructure of most commercially available zirconia systems. It is noteworthy that several manufacturers provide zirconia-based ceramics with various degrees of translucency. Bonding to zirconia is another multifaceted problem. Many clinicians, as in the surveyed sample, complain about loss of retention with such restorations. Recent research findings suggest the use of MDP containing ceramic primers and adhesive in conjunction with sandblasting. ${ }^{(23)}$ About half of the respondents in this survey reported the use of resin-based cement with zirconia restorations. Further research is warranted to investigate the bonding protocol/materials used by clinicians. Evidence-based guidelines may then be formulated and made available to clinicians to achieve predictable outcome of such restorations. 
For anterior aesthetic restorations, indirect laminate veneers remained the most favoured choice by clinicians. However, there was a notable increase in the percentage of practitioners prescribing direct resin composite veneers in comparison to 2008 survey. ${ }^{(4)}$ This trend is reassuring as it indicates the application of minimally invasive, additive and retrievable treatment concepts. It is suggested that improved adhesives, aesthetics and mechanical properties of resin composite systems are considered to have given practitioners confidence in delivering life-like, predictable restorations. Reinforcing such trends should be a priority in both undergraduate and postgraduate programmes.

The prescription of metal-free crowns would appear to have dramatically changed. The percentage of practitioners who routinely prescribed metal free crowns has almost doubled since the time of the 2008 survey. Increased patient expectations and demands for metalfree restorations may be largely responsible for this trend. Additionally, advances in dental biomaterials science have allowed for the production of high strength ceramics that can withstand occlusal forces and produce optimum aesthetic results. Lithium disilicate and zirconia based ceramics were considered among the most trustworthy materials to construct metal free crowns, inlay and onlays by the majority of the respondents. The former material provides excellent aesthetic results and can be bonded to tooth structure in a very predictable manner. The latter however is extremely strong but problematic in some respects, as described earlier.

\section{Conclusion}

Within the limitations of the study, the following can be concluded:

1. More practitioners used light-cured resin composites as core build-up material for vital teeth than reported previously. The use of amalgam continued to be preferred by a large number of practitioners.

2. Dentin pins were still widely used.

3. The use of fibre posts had significantly increased since last investigated 
4. Addition cured silicone impression material continued to be widely used for master impressions for crown and bridgework..

6. Direct resin composite veneers were commonly used as an alternative to indirect porcelain laminate veneers.

\section{Tables}

\begin{tabular}{|l|c|c|}
\hline Table 1. Core build up for vital teeth. Number (\%) \\
\hline Material & $\mathbf{2 0 0 8}$ & $\mathbf{2 0 1 5}$ \\
\hline Amalgam & $430(65)$ & $241(62)$ \\
\hline Light cured resin composite & $317(48)$ & $236(61)$ \\
\hline GIC & $252(38)$ & $48(12)$ \\
\hline RMGIC & $186(28)$ & $74(19)$ \\
\hline Reinforced GIC & $\mathrm{N} / \mathrm{A}$ & $97(25)$ \\
\hline Dual cured resin composite & $131(20)$ & $84(22)$ \\
\hline Compomer & $97(15)$ & $28(7)$ \\
\hline Chemically cured resin composite & $67(10)$ & $30(8)$ \\
\hline Dentin pins & $445(68)$ & $126(34)$ \\
\hline Other & $12(1.8)$ & $4(1)$ \\
\hline & &
\end{tabular}

\begin{tabular}{|l|c|c|}
\hline \multicolumn{3}{|l|}{ Table 2. Post systems Number (\%) } \\
\hline Post type & $\mathbf{2 0 0 8}$ & $\mathbf{2 0 1 5}$ \\
\hline Precious indirect cast & $361(55)$ & $149(39)$ \\
\hline $\begin{array}{l}\text { Non-precious indirect } \\
\text { cast }\end{array}$ & $249(38)$ & $175(46)$ \\
\hline Fibre & $226(34)$ & $243(63)$ \\
\hline Titanuim alloy & $91(14)$ & $44(11)$ \\
\hline Pure titanium & $24(4)$ & $14(4)$ \\
\hline Stainless steel & $71(11)$ & $51(13)$ \\
\hline Do not place posts & $17(3)$ & $15(4)$ \\
\hline
\end{tabular}

\begin{tabular}{|l|c|}
\hline \multicolumn{2}{|l|}{ Table 3. Control of tooth tissue removal } \\
during vital tooth preparation. Number (\%) \\
\hline $\begin{array}{l}\text { Reference to adjacent } \\
\text { and opposing teeth only }\end{array}$ & $90(42)$ \\
\hline $\begin{array}{l}\text { Using preparation burs } \\
\text { of known dimensions }\end{array}$ & $67(31)$ \\
\hline $\begin{array}{l}\text { Using depth cutting } \\
\text { burs }\end{array}$ & $26(12)$ \\
\hline $\begin{array}{l}\text { Using a pre-preparation } \\
\text { matrix }\end{array}$ & $25(12)$ \\
\hline $\begin{array}{l}\text { Do not control the } \\
\text { amount of tooth } \\
\text { removed }\end{array}$ & $8(4)$ \\
\hline
\end{tabular}

\begin{tabular}{|l|c|c|}
\hline Table 4. Impression materials. Number (\%) \\
\hline Material & $\mathbf{2 0 0 8}$ & $\mathbf{2 0 1 5}$ \\
\hline Addition cured silicone & $471(71)$ & $299(78)$ \\
\hline Polyether & $109(17)$ & $85(22)$ \\
\hline Alginate & $75(11)$ & $33(9)$ \\
\hline $\begin{array}{l}\text { Condensation cured } \\
\text { silicone }\end{array}$ & $63(10)$ & $37(10)$ \\
\hline Polysulphide & $18(3)$ & $\mathrm{N} / \mathrm{A}$ \\
\hline Other & $25(4)$ & $5(1)$ \\
\hline
\end{tabular}





\begin{tabular}{|l|c|c|}
\hline Table 5. Materials for crown and bridge. Number (\%) \\
\hline Material & $\mathbf{2 0 0 8}$ & $\mathbf{2 0 1 5}$ \\
\hline Precious alloy & $438(69)$ & $157(43)$ \\
\hline Non-precious alloy & $167(27)$ & $189(52)$ \\
\hline Zirconia & N/A & $213(57)$ \\
\hline
\end{tabular}

\begin{tabular}{|l|c|c|c|}
\hline \multicolumn{5}{|c|}{ Table 6. Luting cements. Number (\%) } \\
\hline Material & $\mathbf{2 0 0 8}($ PFM) & $\mathbf{2 0 1 5}($ PFM) & $\mathbf{2 0 1 5}$ (Zirconia) \\
\hline GIC & $317(48)$ & $180(47)$ & $56(18)$ \\
\hline Zinc phosphate & $186(28)$ & $56(15)$ & $7(2)$ \\
\hline RMGI & $123(19)$ & $108(28)$ & $51(17)$ \\
\hline Resin composite & $71(11)$ & $55(14)$ & $88(28)$ \\
\hline Resin based (metal) & $71(11)$ & $39(10)$ & $15(4)$ \\
\hline $\begin{array}{l}\text { Resin composite } \\
\text { (self-adhesive) }\end{array}$ & $61(9)$ & $50(13)$ & $72(23)$ \\
\hline Compomer & $7(1)$ & $2(1)$ & $2(1)$ \\
\hline
\end{tabular}

\section{References}

1. Brunton PA, Burke T, Sharif MO, Muirhead EK, Creanor S, Wilson NHF. Contemporary dental practice in the UK: demographic details and practising arrangements in 2008. Bdj. 2012;212:11.

2. J T Burke F, H F Wilson N, J Christensen G, W Cheung S, Brunton P. Contemporary dental practice in the UK: Demographic data and practising arrangements2005. 39-43; discussion $27 \mathrm{p}$.

3. Brunton PA, Christensen GJ, Cheung SW, Burke FJT, Wilson NHF. Contemporary dental practice in the UK: indirect restorations and fixed prosthodontics. British Dental Journal. 2005;198:99.

4. Brunton PA, Sharif MO, Creanor S, Burke FJT, Wilson NHF. Contemporary dental practice in the UK in 2008: indirect restorations and fixed prosthodontics. Bdj. 2012;212:115.

5. $\quad$ Burke FJT WN, Brunton PA, Creanor S. Dental practice in the UK in 2015 -Part 1: demographic and practice arrangements. . Br Dent J. 2017; (in submission).

6. N.H. F. Wilson FJTB, P.A. Brunton, S. Creanor, M.T. Hosey, F. Mannocci. Dental practice in the UK in 2015/2016 - Part 2: Aspects of direct restorations, bleaching, endodontics and paediatric dentistry

Br Dent J. 2017; (in submission).

7. Amalgam fillings to be phased down. Bdj. 2013;215:383.

8. Lynch CD, Wilson NHF. Managing the phase-down of amalgam: part II. Implications for practising arrangements and lessons from Norway. Bdj. 2013;215:159.

9. Suh $\mathrm{Bl}$, Feng L, Pashley DH, Tay FR. Factors contributing to the incompatibility between simplified-step adhesives and chemically-cured or dual-cured composites. Part III. Effect of acidic resin monomers. The journal of adhesive dentistry. 2003;5(4):267-82.

10. Bonsor SJ. Are dentine pins obsolete? Dental update. 2013;40(4):253-4, 6-8.

11. Saunders WP, Saunders EM. Prevalence of periradicular periodontitis associated with crowned teeth in an adult Scottish subpopulation. British Dental Journal. 1998;185:137.

12. Fox K, Gutteridge DL. An in vitro study of coronal microleakage in root-canal-treated teeth restored by the post and core technique. International endodontic journal. 1997;30(6):361-8.

13. Bateman G, Ricketts DNJ, Saunders WP. Fibre-based post systems: a review. British Dental Journal. 2003;195:43.

14. Plotino G, Grande NM, Bedini R, Pameijer CH, Somma F. Flexural properties of endodontic posts and human root dentin. Dental Materials. 2007;23(9):1129-35.

15. Nayyar A, Walton RE, Leonard LA. An amalgam coronal-radicular dowel and core technique for endodontically treated posterior teeth. The Journal of Prosthetic Dentistry. 1980;43(5):511-5.

16. Fokkinga WA, Le Bell AM, Kreulen CM, Lassila LVJ, Vallittu PK, Creugers NHJ. Ex vivo fracture resistance of direct resin composite complete crowns with and without posts on maxillary premolars. International endodontic journal. 2005;38(4):230-7. 
17. Tran D, Nesbit M, Petridis H. Survey of UK dentists regarding the use of CAD/CAM technology. Bdj. 2016;221:639.

18. Northeast SE, van N, Johnson A, Winstanley RB, White GE. Metal-ceramic bridges from commercial dental laboratories: alloy composition, cost and quality of fit. British Dental Journal. 1992;172:198.

19. Wassell RW, Walls AWG, Steele JG. Crowns and extra-coronal restorations: Materials selection. British Dental Journal. 2002;192:199.

20. Garvie RC, Hannink RH, Pascoe RT. Ceramic steel? Nature. 1975;258:703.

21. Manicone PF, Rossi lommetti $P$, Raffaelli L. An overview of zirconia ceramics: Basic properties and clinical applications. Journal of Dentistry. 2007;35(11):819-26.

22. Le M, Papia E, Larsson C. The clinical success of tooth- and implant-supported zirconia-based fixed dental prostheses. A systematic review. Journal of oral rehabilitation. 2015;42(6):467-80.

23. Yi Y-A, Ahn J-S, Park Y-J, Jun S-H, Lee I-B, Cho B-H, et al. The Effect of Sandblasting and Different Primers on Shear Bond Strength Between Yttria-tetragonal Zirconia Polycrystal Ceramic and a Self-adhesive Resin Cement. Operative Dentistry. 2015;40(1):63-71. 